\title{
A cultura de avaliação da Universidade Federal do Rio Grande do Sul (UFRGS): entre a avaliação externa e a autoavaliação
}

Nara Maria Emanuelli Magalhães ${ }^{a}$ Cláudia Medianeira Cruz Rodrigues ${ }^{b}$

\section{Resumo}

Este artigo propõe-se a realizar uma análise da trajetória da avaliação na Universidade Federal do Rio Grande do Sul (UFRGS), a partir de entrevistas com os gestores que estiveram à frente da Secretaria de Avaliação Institucional (SAI), desde o seu surgimento nos anos 2000 até 2016 (ou seja, quatro gestores). Destacam-se do contexto mais geral de avaliação nacional as iniciativas locais que foram sendo adaptadas para atender às demandas por uma avaliação mais global, passando pelas diferentes gestões e o respectivo foco de sua atuação durante o processo. Procura-se compreender o modo como a UFRGS, ao longo do tempo, vai constituindo uma cultura de avaliação.

Palavras-chave: Cultura Interna. Autoavaliação. Avaliação Externa. Cultura de Avaliação.

\section{Introdução}

Neste artigo, realiza-se uma breve exposição sobre a história da avaliação institucional no Brasil, os programas de avaliação nacional que foram sendo propostos, e as consequências no modo como as instituições organizaram e planejaram sua avaliação institucional. A seguir, a partir da realização de entrevistas com todos os gestores que estiveram à frente da Secretaria de Avaliação Institucional (SAI) na Universidade Federal do Rio Grande do Sul (UFRGS), desde a sua criação nos anos 2000 (totalizando quatro gestores até o ano de

\footnotetext{
a Universidade Federal do Rio Grande do Sul, Porto Alegre, RS, Brasil.

b Universidade Federal do Rio Grande do Sul, Porto Alegre, RS, Brasil. 
2016), aborda-se o foco de atuação e o desenvolvimento gradativo da cultura da avaliação ${ }^{1}$ no período. As entrevistas foram realizadas com uma abordagem qualitativa, utilizando referenciais das Ciências Sociais, em especial a área de antropologia ${ }^{2}$, entre os quais: Queiroz (1988), Goldenberg (2004). Alguns destaques dos textos foram utilizados para compor a análise e cronologia aqui destacada. As entrevistas foram realizadas de forma semiestruturada, ou seja ${ }^{3}$, a entrevistada ou o entrevistado eram convidados a discorrer de forma livre sobre temas como: o foco da gestão no período, as principais realizações e os principais desafios enfrentados ${ }^{4}$. Espera-se assim contribuir para a contextualização da trajetória de desenvolvimento da avaliação na UFRGS.

\section{Referencial teórico: a avaliação institucional no Brasil}

Segundo Leite (2000), no Brasil a avaliação não é nova, e o ensino de Pós-Graduação já convive com processos avaliativos realizados pela Coordenação de Pessoal de Nível Superior (Capes) desde 1977. A novidade estaria mais relacionada ao ensino de Graduação, que, só a partir dos anos 1990, e, mais recentemente, a partir de 2004, com o Sistema Nacional de Avaliação da Educação Superior (Sinaes), vem sendo avaliado de forma sistematizada pelo Ministério da Educação (MEC) ${ }^{5}$.

Desde o momento em que a Lei de Diretrizes e Bases da Educação (LDB) foi promulgada, em 1996, até o final daquela década, o crescimento do número de instituições foi de 50\% (de 893 a 1.391), e na década seguinte foi ainda maior, passando de $70 \%$ (de 1.391 para 2.391 ), de 2010 a $2013^{6}$.

Um marco ainda mais recente na expansão das instituições de Ensino Superior foi a implantação do Programa de Apoio aos Planos de Reestruturação e Expansão

\footnotetext{
Por cultura da avaliação, entende-se um "conjunto de valores acadêmicos, atitudes e formas coletivas de conduta que tornam o ato avaliativo parte integrante do exercício diuturno das funções universitárias. A cultura da avaliação, para instalar-se, necessita de construção coletiva, com intensa participação da comunidade, tanto nos procedimentos e implementação, quanto na utilização dos resultados (BRAGA; LEITE, 2004)".

2 Para uma discussão metodológica e a especificidade/cientificidade da abordagem qualitativa, ver Magalhães (2008).

3 * Pesquisa realizada sob orientação da Profa. Dra. Claúdia Rodrigues, coautora deste artigo.

${ }^{4}$ O material coletado nas entrevistas foi transcrito para a forma de texto com a ajuda dos estudantes bolsistas Bruno H. G. Ribeiro e Renata S. Tavares, a quem agradecemos.

5 A afirmação da autora refere-se ao final dos anos 1990 e ao início dos anos 2000, confirmando a cronologia aqui destacada. Estas informações encontram-se em Rodrigues (2003, p. 77).

6 Dados obtidos no site do Inep, em: www.Inep.gov.br, analisando quadros que contêm informações sobre o número de Institutos de Ensino Superior (IES) no período de 1991 a 2002, e o Censo da Educação Superior, publicado pelo Instituto Nacional de Estudos e Pesquisas Educacionais Anísio/Diretoria de Estatísticas Educacionais (Inep/Deed), no período de 2010 a 2013 (Inep, 2015).
} 
das Universidades Federais (Reuni), cujas consequencias foram estudadas por autores como Almeida et al. (2019), segundo os quais:

Os objetivos do Reuni para a expansão de vagas no Ensino Superior foram alcançados, resultando em um aumento no número de estudantes no ensino público superior, indo de 336.223 em 2007 para $534.361 \mathrm{em} 2015$, representando um aumento de 59\% (INEP, 2017). No entanto, essa rápida expansão levou a uma desconfiança em relação à qualidade da Educação, com críticas a ofertas não planejadas de cursos, muitas vezes pouco atraentes e não relacionadas à realidade socioeconômica de cada região, resultando em um grande número de estudantes graduados fora do mercado de trabalho (SANTOS et al., 2011). Nesse contexto, como apresentado por Sousa et al. (2011), a alegada inclusão educacional promovida pelo Reuni pode ser criticada e interpretada de maneira oposta, ou seja, ao invés de incluir o aluno, excluiu-o da possibilidade de acesso a um Ensino Superior de qualidade e emancipatório (ALMEIDA et al., 2019, p. 2-3, tradução das autoras).

Ou seja, a expansão proposta através do Reuni, em 2007, resultou num efetivo incremento na ordem de $59 \%$, o que não garante, segundo os autores, uma concomitante expansão da qualidade.

A expansão da Educação Superior, sobretudo da rede privada de ensino, era uma preocupação constante dos estudiosos, nas décadas iniciais do debate aqui referido. A avaliação era vista com desconfiança e predominava o significado negativo. É bastante conhecida no debate, a experiência da Universidade de São Paulo (USP), de 1982. Na época, foi publicada uma lista chamada "Lista dos Professores Improdutivos da USP", que teve ampla repercussão. Mesmo com o caráter extremamente negativo do fato, a partir desse impacto, a comunidade acadêmica reagiu e a USP começou a desencadear seu processo de avaliação, o que impulsionou seu crescimento e a tem colocado no topo de avaliações de qualidade (ANDRIOLA; OLIVEIRA, 2015).

Outros autores, como Dias Sobrinho (2000), salientam a ideia de crise como base da necessidade de avaliação. Para ele, foi a crise econômica e social que originou a ideia de avaliação como forma de distribuição de recursos escassos e orçamentos insuficientes. Segundo o autor, a avaliação não é (ou não deveria ser) instrumento de medida de atividades realizadas por indivíduos, de exposição pública de fragilidades ou ineficiências individuais. Deve ter um caráter de 
aprendizagem, levantando questionamentos filosóficos, éticos e políticos sobre a Universidade, envolvendo vários agentes do processo universitário, coletivamente, e procurando envolver também a comunidade externa no processo. Ristoff (1999) também se refere a crises que, através do processo de avaliação, podem ser indicadas e superadas: crises de gestão, de modelo, de autonomia, de função, enfim, de qualidade, as quais poderiam ser revertidas através do monitoramento avaliativo constante.

Esses significados de "crises" permeavam a discussão sobre avaliação em meados dos anos 1980 até os anos 1990, que pode ser considerado um período inicial da avaliação do Ensino Superior no Brasil. Naquela época, podiam-se destacar algumas iniciativas, como a realizada pela Associação Nacional de Docentes do Ensino Superior (Andes), em 1982, que desencadeou discussões, com o objetivo de superar as tensões que envolviam o meio acadêmico, propondo, então, a avaliação institucional. Mas foi só no ano seguinte, em 1983, que o MEC instituiu o Programa de Avaliação da Reforma Universitária (Paru), que vigorou até 1986 (RODRIGUES, 2003).

Ainda em 1986, o Conselho de Reitores das Universidades Brasileiras (Crub), entidade representativa de setores privados do Ensino Superior, pautou a necessidade de propor parâmetros de avaliação e desenvolver sistemas de avaliação, incluindo a avaliação de desempenho. Essas iniciativas culminaram na proposição, pelo governo federal, do Grupo Executivo para Reformulação do Ensino Superior (Geres). A proposta desse grupo, apresentada ao Ministério, não foi muito bem aceita pela comunidade acadêmica, pois pretendia, segundo Leite (2000), ranquear as instituições, distinguindo-as quanto às suas funções.

Havia uma preocupação com recursos e uma vinculação da ideia de avaliação com a medida dos custos das Universidades federais. Com esse debate, aliado a outras políticas do governo federal à época, tornou-se frequente, na mídia, uma crítica realizada às Instituições de Ensino Superior no Brasil, sobretudo às instituições públicas. Algumas Universidades reagiram, passando a promover seus próprios seminários de avaliação, e desencadeando seus processos de avaliação, como foi o caso da Universidade de Brasília (UNB), da Universidade Federal do Paraná (UFPR) e da USP (RODRIGUES, 2003).

Também a Universidade Estadual de Campinas (Unicamp) começou sua experiência de avaliação em 1990, construindo um processo de avaliação democrático, que promovia a participação da comunidade, com ênfase nas análises qualitativas de processos acadêmicos e na melhoria da qualidade (DIAS SOBRINHO, 1994). 
Leite (2000) enfatiza que havia certa tensão, naquele período, nas relações entre Estado e Universidades. Para resolvê-las, o governo criou a Comissão Nacional de Avaliação (CNA), cuja Coordenação ficou a cargo do Prof. Hélgio Trindade, então Reitor da UFRGS. O trabalho que iniciou com essa comissão nacional deu origem, em 1993, ao Programa de Avaliação das Universidades Brasileiras (Paiub). Como se pode perceber, a UFRGS esteve diretamente envolvida numa proposição de avaliação das Universidades desde seu início.

De acordo com os princípios do Paiub, a avaliação deveria ter três momentos: a autoavaliação da instituição, a avaliação externa e a síntese entre as etapas anteriores, com a confrontação dos dados da avaliação externa e interna, contando com a presença de membros da instituição e especialistas convidados (ANDRIOLA; OLIVEIRA, 2015, p. 492). Dias Sobrinho (1994) destaca que apenas quatro anos depois da implantação do Paiub, $80 \%$ das Universidades iniciaram avaliações adotando os princípios do Programa. Porém, à medida que a adesão ia crescendo, já entravam em vigor novas regras.

Segundo Andriola e Oliveira (2015), em outubro de 1996 entrou em vigor o Decreto $\mathrm{n}^{\circ} 2.026$, que ditou regras para o processo de avaliação dos Cursos e das IES. O novo programa estava subdividido em cinco modalidades: o Exame Nacional de Cursos (ENC); as Visitas in loco, feitas pelas Comissões de Especialistas; a Autoavaliação Interna, concretizada pelo Paiub; a Avaliação dos Dados Cadastrais, executada pela Secretaria de Desenvolvimento, Inovação e Avaliação Educacional (SEdai) e a Avaliação, realizada pela Capes.

Nessa nova proposta, foi o ENC, ou Provão, que se destacou. Essa prova era elaborada por comissões específicas para cada curso, que definiam os conteúdos e habilidades a serem avaliadas. Também integravam esse processo as visitas in loco aos cursos de Graduação, que eram orientadas por um manual, contendo indicadores e padrões de qualidade a serem examinados ${ }^{7}$.

Essas iniciativas institucionais influenciaram a forma como as IES realizaram suas avaliações e, sem dúvida, contribuíram para que algumas resistências à cultura da avaliação se expressassem, pois muitas mudanças estavam sendo aplicadas em curto período de tempo. Após essa fase de experimentações e de busca pelo

Sobre o ENC, ou Provão, há um importante estudo realizado por Verhine, Dantas e Soares (2016), abordando uma comparação com outro que o sucedeu, o Exame Nacional de Desempenho de Estudantes (Enade). A reflexão dos autores destaca muitos pontos comuns entre os exames, apesar de o segundo ter representado uma busca de superação das limitações do primeiro. 
melhor modelo, no período subsequente, com a implantação do Sinaes, o processo de avaliação institucional se consolidou.

Seria impossível, no âmbito deste artigo, reproduzir a ampla discussão que vem sendo realizada ao longo dos anos, a respeito da avaliação da Educação Superior. Muito tem-se analisado sobre o papel da avaliação frente às instituições de ensino, sobre seus resultados contribuírem para a democratização e/ou reprodução de um sistema social desigual, para alavancar, ou não, uma Educação transformadora (FREIRE, 2011). Ao longo dessa abordagem, trouxemos autores que aprofundam esse debate, como Ristoff (1999; 2013), Dias Sobrinho (1994; 2000), Leite (2000), Vasconcelos; Gomes (2016), entre outros, que problematizam essas questões.

Ainda que as críticas aos modelos permaneçam, e as propostas de melhorias sempre possam ser apresentadas, atualmente é inegável o reconhecimento da importância da avaliação, e cada vez mais se consolida um campo de reflexão que trata a avaliação como construção de conhecimento, ou seja, como campo científico.

\section{A visão dos gestores de avaliação na UFRGS}

Para conhecer a visão dos gestores de avaliação na UFRGS, no período de 2000 a 2016, foram realizadas entrevistas. Para localizá-los, recorreu-se aos registros institucionais. As entrevistas foram realizadas com base em abordagem qualitativa e trascorreram na forma semiestruturada, ou seja, a entrevistada ou o entrevistado eram convidados a discorrer de forma livre sobre temas como: o foco da gestão no período, as principais realizações e os principais desafios enfrentados. A seguir, construímos uma cronologia e os destaques de cada uma das gestões de acordo com o ponto de vista dos entrevistados.

A primeira Secretária de Avaliação Institucional da UFRGS atuou no período de 2000 a $2002^{8}$. Segundo seu depoimento, o período de criação da SAI não significava o inicio da avaliação na instituição, pois já havia avaliação na UFRGS. Ela ressaltou que a principal atividade de avaliação na Universidade, na época, estava relacionada à preparação dos alunos para o chamado Provão e a análise cuidadosa de seus resultados.

\footnotetext{
8 Os entrevistados serão denominados Secretários de Avaliação (SA) e numerados na ordem de 1 a 4, com uma breve descrição sobre sua área de formação, que não permita identificá-los. Nesse sentido, cabe destacar que a primeira gestora possui formação de Graduação em Licenciatura em Letras, pela UFRGS, Mestrado em Letras, pela UFRGS e Doutorado em Literatura Brasileira, pela USP.
} 
Além dessa centralidade assumida pelo Provão na Avaliação Institucional, como aconteceu em outras Universidades (ANDRIOLA; OLIVEIRA, 2015), percebese, no depoimento, os significados atribuídos à avaliação no período, cercados de dúvidas e desconfianças, tanto pelo fato de a instituição ser avaliada, como pela maneira como surgiam as propostas:

[...] ela, a avaliação em si, no início ela provocava certas dúvidas, uma certa desconfiança, até nos professores... porque não é bom ser avaliado, não é bom no sentido de não ser confortável ser avaliado. [...] Bom sempre é sim, mas sempre tem temores, enfim. Não sabíamos bem como é que surgia aquela avaliação e inicialmente era uma avaliação que vinha de cima, não é. Muitas avaliações participativas que hoje ainda ocorrem na Educação brasileira, eram conhecidas (SA1).

Nota-se que na UFRGS, as visões iniciais sobre a avaliação acompanhavam o significado atribuído por outras Universidades tais como: Universidade de Campinas, Universidade de São Paulo, Universidade Federal do Paraná e Universidade de Brasília, refletindo dúvidas, e questionando o modo como as propostas chegavam, num contexto institucional onde vigoravam valores como o da participação, sem valorizá-la. Vinha "de cima". Portanto, sem diálogo ou construção anterior com a comunidade.

Mas, gradativamente, a comunidade universitária foi sendo levada a uma maior participação no processo, e a apresentar projetos que fortalecessem uma visão de que a Universidade, sendo pública, precisava prestar contas à comunidade externa, uma vez que esta viabilizava a existência de recursos federais que the davam sustentabilidade:

[...] então, começaram a surgir projetos, a comunidade dos nossos professores se congregava... [...] Nesse aspecto eu acho que houve uma mudança de mentalidade do polo acadêmico de professores da UFRGS. Ele se tornou mais forte, no sentido de melhorias e de caminhos para que ele pudesse desenvolver o seu percurso também acadêmico. Sempre buscando [...] preservar a função da Universidade pública. Mas de qualquer maneira a Universidade pública ela tem a sua especificidade (SA1).

A gestora também se referiu ao Provão e ao modo como seus resultados foram sendo recebidos na UFRGS: 
[...] Depois de cada avaliação de Provão, nós recebíamos um material produzido pelo Ministério, muito bem produzido, em que se fazia um levantamento de dados. [...] era uma avaliação diagnóstica. [...] Era uma avaliação quantitativa propondo-se, a partir daquilo, que se fizesse gestões qualificadas, utilizando aqueles dados. [...] os primeiros resultados [do Provão] dos quais eu fui próxima, mostravam o que nós já sabíamos: que a qualidade acadêmica da UFRGS era muito boa, [...] que a formação dos professores estava em alta. A UFRGS ainda naquela época já era uma das instituições com maior número de profissionais qualificados, tanto em nível de mestrado quanto em nível de doutorado. [...] E mostrava também as nossas deficiências físicas, nossos espaços físicos e estruturais. [...]. Havia o início de uma certa atividade internacional de um contato com outras Universidades (SA1).

Percebe-se que, na medida em que a avaliação institucional trazia dados que exaltavam pontos positivos, gradativamente a comunidade foi sendo conquistada para sua realização. Com isso, e com a vocação institucional para o debate, que incluía alto índice de autocrítica, a avaliação foi firmando-se.

Demonstrando o grande interesse da comunidade acadêmica na participação e nos debates sobre os rumos da avaliação, a estrutura da avaliação na UFRGS, à época, mesmo em seu início, já contava com os Núcleos de Avaliação das Unidades (NAUs):

[...] Foi durante a gestão do PAIUFRGS (Programa de Avaliação Institucional da UFRGS) e o que me antecedeu, a fundação dos NAUs. Quando nós vimos, já havia muitas discussões, muitas novidades com o NAU aí fora [fora da Administração Central] e isso já antecedia essa iniciativa, já antecedia a minha entrada na Universidade. [...] do ponto de vista estrutural na gestão, a Secretaria era muito pequena.... Mas havia muitas qualificações de avaliação já na comunidade, os NAUs também estavam começando. Havia uma discussão muito forte. Tudo era muito bem congregado, se percebia cada vez mais essa necessidade de trabalho conjunto [...]. Havia um representante da comunidade, um representante dos professores que eram escolhidos. E funcionavam junto aos cursos de Graduação, nas Comissões de Graduação (Comgrads) e junto às direções no sentido de estimular essas iniciativas e essas participações. Eram coisas que estavam sendo iniciadas (SA1). 
No período seguinte, de 2002 a 2008 , a gestão esteve a cargo de outra professora ${ }^{9}$, que, anos antes de assumir como Secretária de Avaliação, já participava dos processos de avaliação em construção na UFRGS:

Foi no ano de 1993 que o Paiub (Programa de Avaliação Institucional das Universidades Brasileiras), foi lançado pelo Ministério da Educação com a possibilidade de adesão das Universidades. A UFRGS imediatamente se voluntariou e trabalhamos em uma comissão de professores da Universidade junto à Pró-Reitoria de Graduação, montando então o projeto de Avaliação Institucional interna da Universidade. O início, depois do grande projeto, foi trabalhar com todas as Unidades acadêmicas da Universidade [...]. Então essa comissão fez a proposta para a Universidade, em uma grande reunião com todas direções de Unidade, e professores, alunos e técnicos. Os diretores levaram nas unidades a proposta, lá discutiram. Não estou exatamente lembrada do percentual de unidades, mas foi um percentual muito grande, próximo de cem por cento (SA2).

Conforme pode-se perceber no seu relato, na UFRGS, a adesão ao Paiub foi grande e foi colocada em prática, quase de modo imediato após seu lançamento pelo Governo Federal. Além do grande envolvimento interno, houve também a fase de receber as visitas externas para avaliação:

A comissão teve um grande projeto [...] apresentado em 1993, porque o Paiub tinha uma filosofia e uma proposta de como encaminhar o trabalho, que tivesse um mínimo comum entre todas as Universidades que participaram do programa. Então tivemos esse desenvolvimento dentro da UFRGS, onde praticamente $100 \%$ das unidades aderiram [...] foi uma atividade completamente nova, difícil de ser feita pelos professores, pelos próprios alunos e técnicos [...] nós conseguimos fazer evoluir. Nesta proposta do Paiub, tinha também, depois dessa avaliação externa, uma visita de especialistas. Eles vieram, [...] conhecer o trabalho que foi feito nas diferentes unidades e trabalharam na perspectiva de uma banca [...]. Eles vieram para conhecer e para chancelar, como um olhar externo que corrobora o olhar interno, com uma banca de 3 professores de diferentes Universidades (SA2).

\footnotetext{
9 A professora SA2 assumiu a Secretaria de Avaliação na metade do segundo mandato da Reitora Wrana Panizzi, no período entre 2002 e 2003, e manteve-se, no período de 2004 a 2008, na gestão do Reitor José Carlos Hennemann. Possui formação de Mestrado e Doutorado em Educação pela UFRGS.
} 
Já havia uma experiência forte da UFRGS com a avaliação interna, mas a novidade, na época, era justamente preparar-se para ser avaliado de fora, receber as visitas de avaliação de pares. Parece que esse desafio foi bem aceito, uma vez que, mesmo quando foi extinto o Programa Nacional, localmente decidiu-se pela continuidade:

O Paiub se extinguiu, por falta de verba, se não estou enganada, então a UFRGS resolveu manter o trabalho. Então o nome que foi dado foi PAIUFRGS. E continuando com esse trabalho interno, com os Núcleos de Avaliação (SA2).

A professora relatou o modo como a Secretaria atuava, propondo atividades de sensibilização e capacitação, realização de seminários, entre outras, procurando fortalecer e estimular a avaliação interna:

Cada NAU teve liberdade de fazer sua autoavaliação a partir da percepção de sua própria comunidade. Não houve um modelo fechado, nós trabalhamos muito com a sensibilização, com apoio aos Núcleos, oferecendo materiais de estudo, oferecendo seminários, e todo o trabalho pedagógico para que eles pudessem se apoderar dessa lógica de trabalho dentro da instituição, que conhecia a avaliação que era feita pelos professores em relação aos alunos. Diga-se de passagem, que antes nós tínhamos avaliação sim, da Pós-Graduação pela Capes. Mas, de qualquer forma, era alguma coisa assim que não entrava dentro da Universidade. Essa sim era uma avaliação interna (SA2).

A entrevistada forneceu também um histórico do surgimento da avaliação dos professores pelos estudantes através de questionários, num modelo que inicialmente foi proposto na área de Ciências Agrárias e depois adaptado para toda Universidade:

A UFRGS continuou com seu trabalho, a avaliação do professor pelo aluno ela foi aperfeiçoada [...] o modelo ainda era usado, ele foi criado por determinada área [agrárias], todos os semestres os alunos avaliavam os professores e as disciplinas. O modelo com questionários feitos pelo aluno surgiu lá, tinha alguma outra unidade também [com] algum modelo, mas o nosso [...] trabalhava com as instalações, com o conhecimento do professor, [...] a capacidade pedagógica do professor, as avaliações feitas pelos professores, então ele era um instrumento mais abrangente. [...]. Eu atuava nessas unidades [...]. Minha formação é pedagogia, só que a Associação 
Brasileira de Educação Agrícola Superior criou um grande projeto nacional para as agrárias, que eram as unidades de ações pedagógicas, eu fui trabalhar aqui na UFRGS nessa unidade. E lá nós começamos esse trabalho com avaliação, o trabalho maior foi o currículo dos cursos que nós trabalhamos com professores e alunos durante seis anos, que era o período que tinha notificações nos currículos. E aí nós decidimos aplicar uma metodologia de uma professora Tânia Fisher que também era da UFRGS, que depois foi para a Universidade Federal da Bahia. Os nossos trabalhos foram tão completos, que nós apresentamos em todas as Universidades brasileiras (SA2).

Essa experiência inicial de avaliação, que contou com um grupo percorrendo as várias unidades da federação, divulgando um modelo de questionário de avaliação dos docentes pelos discentes, pode ter contribuído para tornar a metodologia de avaliação da UFRGS conhecida nacionalmente, bem antes da implantação do Sinaes.

Voltando à Avaliação da Universidade, quando o Sinaes estava sendo gestado, uma das instituições que estavam coordenando, foi a UFRGS. Justamente por todo esse trabalho que nós tínhamos aqui. E muitos dos nossos movimentos foram aproveitados pela comissão do Sinaes [...]. Foi um reconhecimento do trabalho... E quando veio o Sinaes... nós tínhamos na Graduação a avaliação interna. Aí tivemos, claro, que dar um salto de qualidade para poder absorver as outras visões que o Sinaes trazia (SA2).

Mesmo tendo contribuído para a elaboração do Sinaes, a Universidade ainda não estava totalmente preparada para a proposta de avaliação de todas as outras dimensões que o novo sistema previa, e teve que se aperfeiçoar. $\mathrm{O}$ foco, que era mais direcionado à avaliação interna, precisou voltar-se para a avaliação externa.

O próximo gestor à frente da Secretaria de avaliação foi um professor da área de Engenharia ${ }^{10}$, no período de 2008 a 2012. Em sua entrevista, ele relatou que uma das primeiras questões a enfrentar em sua gestão foi o fato de que a UFRGS ainda não tinha um Plano de Desenvolvimento Institucional (PDI). Sabendo que

\footnotetext{
${ }^{10} \mathrm{O}$ período de exercício como Secretário de Avaliação corresponde à primeira gestão do Reitor Carlos Alexandre Netto, de 2008 a 2012. A formação do gestor SA3 inclui Graduação em Engenharia Mecânica, pela UFRGS, e Doutorado em Engenharia Mecânica, pela Universidade Nova de Lisboa (UNL), Portugal.
} 
a elaboração de um PDI seria um processo longo, o entrevistado relatou a busca de amparo legal para encontrar alternativas:

[...] ao amparo da legislação vigente naquela altura, era possível um Plano de Gestão do Reitor, aprovado, que pudesse subsidiar informações da eventual comissão de avaliadores aqui na UFRGS. Aí essa questão do Plano de Gestão passou a ser o nosso primeiro problema. Porque na realidade [...] tinha um prazo de seis meses para ser aprovado. Não era só apresentar no Conselho, tinha que estar aprovado (SA3).

Todos os setores da administração da Universidade envolveram-se no trabalho de detalhamento do Plano de Gestão, para chegar a um formato que pudesse ser apresentado a uma comissão externa de avaliadores. Os frutos do esforço coletivo serviram não só para preparar a avaliação externa, pois internamente solidificou-se a identidade institucional. Todos os envolvidos tiveram claro quais os objetivos no período, quais as metas e o que seria feito para alcançá-las.

Superada essa fase de aprovar um Plano de Gestão que pudesse subsidiar avaliações, novos desafios se apresentaram: a UFRGS havia sido colocada pelo MEC numa lista das primeiras Universidades a serem avaliadas. A justificativa para essa prioridade era a grande experiência da Universidade com avaliação, e a identificação, por parte do MEC, de alguns arquivos postados eletronicamente, que foram considerados equivalentes ao PDI. Em função dessa Avaliação Institucional, a SAI precisou propor uma série de medidas preparatórias, inclusive junto à Comissão Própria de Avaliação (CPA):

Nós ainda não tínhamos os relatórios da CPA, nosso sistema de autoavaliação institucional, inseridos [eletronicamente] no sistema do MEC. A última versão tinha sido feita dois ou três anos antes, em papel. E era um outro contexto, uma outra maneira de organizar relatórios que não era ainda aquilo que era exigido pelo MEC para a avaliação. [...]. Aí nós tivemos que produzir um relatório que cobrisse os três últimos anos (SA3).

Com base na experiência anterior, novamente a comunidade foi mobilizada para produzir e organizar dados. O resultado de todo esforço, novamente, foi recompensado. Após encaminhar esse Relatório ao Conselho, a Universidade, então, preparou-se para receber a Comissão de avaliadores externos, e foi bem avaliada. 
Após essa visita, foi elaborada uma nova nota técnica do MEC, determinando que as Universidades deveriam passar por um recredenciamento institucional, e a UFRGS novamente estava entre as primeiras a serem avaliadas. Mais uma vez, houve a dedicação do coletivo a um trabalho gigantesco, num curto prazo, envolvendo toda comunidade acadêmica, e a Universidade conseguiu produzir seu PDI. Vários relatórios de autoavaliação também foram produzidos na época, procurando vincular os dois processos - de planejar a gestão e de refletir sobre a mesma - de modo a contemplar as exigências legais sobre a autoavaliação.

Enquanto isso, a CPA, com essa denominação, também era nova na Universidade ${ }^{11}$. Apesar de toda experiência institucional com avaliação, a composição de uma comissão com status de Conselho Superior, que guardasse autonomia em relação à gestão, era algo novo, previsto numa legislação recente e aprovada em portaria também recente, o que se refletia no trabalho da comissão.

Segundo o gestor SA3, a mudança que a UFRGS estava enfrentando era uma mudança geral, no próprio foco da avaliação, que não teria mais um peso maior na avaliação interna:

[...] Mas não havia como a gente ficar fazendo coisas dentro da CPA e fazendo a avaliação interna, porque daqui a pouco não é mais nada daquilo que se precisava. Era outra coisa, outro relatório, outro tipo de informação que o Inep queria e que claro, a lei do Sinaes já disse que o órgão principal responsável para fornecer informações ao Inep é a CPA (SA3).

Logo após a regularização da avaliação institucional, com todos os requisitos legais cumpridos, novos desafios apresentaram-se. Havia desafios internos com relação ao significado da avaliação (e do setor de avaliação) no período: muitas resistências, e o setor era visto quase como um órgão de auditoria interna. Era necessário todo um trabalho da SAI para demonstrar que o trabalho era a favor da Universidade. O professor também se referiu à forte cultura institucional da UFRGS, com valorização da forma própria de organização, o que, de algum modo, poderia explicar as resistências. Segundo ele: "a cultura interna da UFRGS é de que as coisas são feitas à moda de dentro da UFRGS, e isso basta para resolver os nossos problemas".

\footnotetext{
${ }^{11}$ As Portarias de constituição da CPA na UFRGS são as seguintes: Portaria n 1.766, de julho de 2004, e Portaria $n^{\circ} 3.395$, de dezembro de 2004. A Decisão do Consun que aprova o regimento da CPA é a de número 184/2009. Apesar da experiência da UFRGS de possuir qualificadas Comissões de Avaliação locais desde a instituição do Paiub em 1993, a CPA estabelecida pela Lei do Sinaes em 2004 possuía uma série de novas atribuições e competências.
} 
Refletindo a respeito dessa cultura interna contemplar ou não a avaliação, o professor esclarece: "Assim, existia uma cultura de administração interna. O pessoal acreditava tanto que considerava melhor que a externa". Portanto, essa cultura organizacional podia, em alguns momentos, representar até uma barreira para a consolidação de uma cultura de avaliação.

A seguir, convidado a refletir sobre a colocação da UFRGS em primeiro lugar no ranking nacional, o professor posicionou-se atribuindo o resultado à atenção que foi dada à regulação, que, segundo ele, não pode ser tratada separadamente da avaliação:

[...] A UFRGS nunca tinha sido a primeira colocada no MEC. E o ano em que nós terminamos o nosso mandato foi o primeiro ano em que a UFRGS tirou o primeiro lugar. Todo aquele longo esforço de colocar as coisas nos eixos, foi o primeiro ano que nós pudemos nomear: agora estamos no topo! [...] porque muito mais difícil do que tu sair bem na avaliação, é tu sair bem na regulação. Muito mais complexo. Mas o que as pessoas não entendem, e aí é que está o problema, é que ao se autoregularizar na regulação tu consegue um ponto na avaliação. As pessoas não conseguem entender, elas estão tratando as coisas separadas. [...] se tu perdes o foco de te manter dentro dos parâmetros da regulação, o problema na avaliação começa a aparecer (SA3).

Assim, terminado esse período, e devidamente organizada com base na legislação externa, a área de avaliação da UFRGS partia para novos desenvolvimentos.

O gestor seguinte da SAI, que assumiu no período de 2012 a 2016, foi um professor da área de Informática ${ }^{12}$, e a sua gestão retomou, como foco central, a questão da autoavaliação:

[...] o foco da nossa gestão tem sido na autoavaliação institucional [...] ela tem vários objetivos, um deles é apoiar a gestão da Universidade, os gestores da Universidade em geral, e em segundo lugar a avaliação institucional também dá para a sociedade um feedback, um retorno dos recursos aplicados. Se nós estamos aqui usando recursos do contribuinte, o contribuinte que está lá

\footnotetext{
${ }^{12}$ O exercício como Secretário de Avaliação Institucional deu-se na segunda gestão do Reitor Carlos Alexandre Netto, no período de 2012 a 2016. Sua formação inclui Graduação em Engenharia Elétrica, pela UFRGS, Mestrado em Informática, pela Pontifícia Universidade Católica do Rio de Janeiro (PUC-RJ) e Doutorado em Der Naturwissenschaften - Informatik - Universitat Stuttgart.
} 
fora quer saber se aquele trabalho - as atividades, os processos da Universidade - estão sendo feitos com qualidade. E depois também tem o objetivo de verificar a qualidade dos processos da Universidade, processos de pesquisa, de extensão, sustentabilidade financeira, a missão, o plano institucional, a assistência estudantil etc... Então nós temos o foco que é de trabalhar na Universidade em cima das 10 dimensões do Sinaes (SA4).

Para dar conta da complexidade das dimensões previstas na Lei do Sinaes, a SAI trabalhou intensamente para implementar instrumentos de avaliação propostos pela CPA e para extrair dados que pudessem ser medidores de qualidade:

Trabalhamos utilizando como dados aqueles que são extraídos dos questionários de avaliação, e infelizmente a gente só conseguiu construir até o final da gestão quatro instrumentos de avaliação: a avaliação do docente pelo discente, a avaliação da Pós-Graduação, a autoavaliação docente e a avaliação dos professores do colégio de aplicação. [...] quem constrói o questionário é a CPA, ela é que toma os processos, [...] produz os questionários de avaliação, com o quais se realizam coletas de dados de avaliação, a Secretaria de Avaliação é um órgão executivo da CPA (SA4).

O professor diferenciou a avaliação de produtos e de processos, esclarecendo que, na sua visão, a SAI trabalhava com o segundo tipo:

Então, o foco é a avaliação da Universidade, [...] o foco da SAI nessa gestão é avaliação dos processos, uma vez que, pelo menos, a Pós-Graduação é avaliada com base nos seus produtos pela Capes, portanto, alguém já faz isso, e a avaliação da Graduação com base nos produtos é feito pelo Enade, portanto não faz sentido a SAI ficar analisando produtos da Universidade. Claro que nós temos um questionário já pronto, mas que não entrou em operação ainda, que é o questionário do egresso, onde muita informação a gente pode obter com base no sucesso ou fracasso dos profissionais formados pela UFRGS no mercado de trabalho (SA4).

Na continuidade, abordou também as mudanças realizadas à frente da gestão da SAI, especificando o trabalho em departamentos: 
Nós procuramos dividir o trabalho, e criamos um departamento de regulação [...] de forma a resolver todos os problemas de credenciamento, reconhecimento e renovação de reconhecimento, todo esse papel cartorial que o departamento de regulação possui no sentido de registrar corretamente as informações no sistema e-MEC. Criamos também o departamento de avaliação que é [...] o departamento que se preocupa com a implementação dos instrumentos de avaliação da CPA. Estamos até tentando criar um núcleo de Análise de Sistemas, de Tecnologias da Informação, para se preocupar com essa parte computacional, e para construção de questionários, coleta de dados, banco de dados, enquanto que outro núcleo de estatística [...] pode pegar os dados e fazer uma análise, trabalhar esses dados, para dali tirar informações de avaliação (SA4).

Quanto aos NAUs, considerou que, no início da gestão, encontravam-se novamente num limiar de necessidade de revitalização, e passaram a receber dados de avaliação para análise:

Então a primeira decisão foi no sentido de fortalecer os NAUs. O fortalecimento se deu com a formação dos Fóruns dos NAUs na nossa gestão. Em segundo lugar eles recebem dados de avaliação do ano anterior, todos os dados de avaliação relativamente à sua unidade e fazem um trabalho semelhante ao da CPA, ou seja, tirar conclusões a partir dos dados qualitativos e quantitativos, tirar conclusões a respeito das fragilidades e potencialidades de suas unidades, e isso também deve ser levado aos gestores da unidade, num trabalho semelhante que a CPA faz na Universidade. Então nós temos anualmente duas grandes avaliações: a da CPA que olha a Universidade como um todo e o Núcleo de Avaliação que olha cada unidade em particular (SA4).

O Relatório de Autoavaliação Institucional (Raai) foi outro trabalho que passou por melhorias na sua gestão. Realizado anualmente, sob coordenação da SAI, e aprovado pela CPA, sua elaboração envolveu tanto os órgãos da Administração Central quanto os NAUs, que participaram da redação do texto. O professor considerou a possibilidade de avançar ainda mais no formato desse relatório:

O relatório de autoavaliação institucional [...] nós herdamos [...] e a gente procurou fazê-lo da melhor maneira possível, mas a 
metodologia de construção desse relatório é antiga, vem desde as primeiras gestões, fazer essa autoavaliação através das PróReitorias. Mas eu acho que futuramente essa metodologia de construção do Raai via gestores da Universidade deve desaparecer e a CPA deve ela própria fazer a avaliação como muitas Universidades fazem (SA4).

Convidado a discorrer se o que estava faltando na Universidade era a reflexão sobre a sua própria qualidade, esclareceu:

[...] não só sobre a sua qualidade, mas sobre a avaliação como instrumento para gestão, o que é que os gestores querem ver, se estão aptos para saber [...] quais são as fragilidades, quais os pontos que merecem uma atuação e muitas vezes eles não sabem [...]. É importante detectar essas fragilidades dos processos para que a gente chame os gestores e diga quais são os problemas que estão acontecendo, e a partir daí o que é que eles têm que fazer para melhorar a qualidade, isso é um problema de gestão, já foge da avaliação, que já fez o seu papel (SA4).

Ou seja, a avaliação, para ser efetiva, precisa ser um instrumento para a gestão. Segundo o gestor, uma instituição não pode andar às cegas, sem saber quais os problemas que devem ser enfrentados e resolvidos.

Sua abordagem aproxima-se da visão de alguns especialistas em avaliação que discutem indicadores, refletindo sobre a sua utilidade para o planejamento:

[...] os indicadores devem ser encarados como o que na realidade são: artefatos de alcance limitado, ou seja, de eficácia relativa [...]. Por que, então, sua relevância e acentuada difusão, verificadas, atualmente, no campo educacional? Sem dúvida alguma, o motivo principal se encontra em duas características intrínsecas aos indicadores: (i) caráter sintético e (ii) capacidade para orientar a tomada de decisões (ANDRIOLA; ARAÚJO, 2018).

Assim, a abordagem do gestor entrevistado aproxima-se dessa visão de que os indicadores, por si só, não teriam significado, porém, se os mesmos servirem de base para o planejamento e para a implementação de melhorias, adquirem relevância. 
Outra iniciativa na direção de examinar indicadores e elaborar diagnósticos sobre a instituição, foi a proposta da "Semana de Avaliação" na Universidade. Tratou-se de um momento em que a CPA realizou um encontro com os gestores da Administração Central (Reitor, Vice-Reitor, Secretários e Pró-Reitores) e os NAUs realizaram encontros com os gestores das Unidades Acadêmicas (Diretores, Chefes de Departamento, Coordenadores de Comgrads). Na ocasião, os gestores receberam os resultados das avaliações do ano anterior e os diagnósticos, para proporem ações de melhoria da qualidade.

Alguns desafios que permanecem na abordagem de avaliação institucional referemse às lacunas nos indicadores propostos pelo Sinaes, onde permanecem invisíveis as preocupações com internacionalização e inovação, por exemplo. A UFRGS tem participado de redes latino-americanas de acreditação de cursos, as quais se constroem como alternativas às tentativas de ranqueamento internacional, com objetivos exclusivamente mercadológicos, para os quais muitos pesquisadores têm alertado. (SANTOS; LEITE, 2019). Os movimentos de cooperação e integração, em matéria de Educação Superior, são significativos, e a organização em redes pode e deve contribuir para trazer à tona conhecimentos emergentes e a qualidade local e regional da Educação Superior.

\section{Considerações Finais}

A trajetória da avaliação na UFRGS mostra que a mesma tem sido bastante valorizada e tem demonstrado forte tradição de participação democrática e envolvimento da comunidade nos trabalhos internos e externos para constituição do campo. Verifica-se uma alternância de foco nas várias gestões entre avaliação externa e interna, num processo que demonstra a busca do ponto de equilíbrio entre atendimento à legislação externa e valorização de uma cultura de avaliação local.

Na primeira gestão, tem-se o foco voltado para iniciativas externas, como a realização do Provão e os diagnósticos recebidos do MEC, mobilizando e motivando a comunidade interna, com participação dos NAUs, que já haviam sido criados na época do PAIUFRGS.

Na segunda gestão, tem-se o fortalecimento da autoavaliação, com a continuidade do trabalho com os NAUs, forte participação das unidades, e a continuidade da realização da avaliação interna do trabalho dos docentes através de questionários, mantendo, porém, um forte diálogo com a comunidade externa, com o início do recebimento de comissões externas de avaliação. 
$\mathrm{Na}$ terceira gestão, tem-se o foco voltado novamente para o externo, buscando $\mathrm{o}$ atendimento à legislação nacional, exigindo uma reorganização interna, com a regularização do PDI, de Relatórios de Gestão e de Autoavaliação, atualização de informações sobre os cursos no sistema e-MEC. Houve incremento do recebimento de avaliações externas, inclusive o próprio recredenciamento da UFRGS, além da formação da CPA nos moldes estabelecidos pelo Sinaes, e da realização do Enade.

Na gestão de 2012 a 2016, a UFRGS voltou-se novamente para a autoavaliação, com o fortalecimento e a especialização do trabalho da CPA, dos NAUs e da própria SAI, considerando a avaliação como uma instância que fornece subsídios para a gestão promover ações de melhoria.

Analisando essa trajetória, chega-se, portanto, ao período atual de desenvolvimento da avaliação na UFRGS, com a percepção de que o equilíbrio entre a autoavaliação e a avaliação externa pode ser a chave para compreender o fortalecimento local da cultura de avaliação. 


\section{The Federal University of Rio Grande do Sul (UFRGS)' evaluation culture: between external evaluation and self-assessment}

\section{Abstract}

This article proposes to carry out an assessment of the trajectory analysis UFRGS, from interviews with managers who were ahead of the Secretaria de Avaliação Institucional (SAI) since its inception in 2000 to 2016 (ie four managers). It highlights the more general context of national evaluation local initiatives that have been adapted to meet the demands for a more comprehensive evaluation through different administrations and their focus of its operations during the process. Wanted understand how UFRGS, over time, will constituting an evaluation culture.

Keywords: Internal Culture. Self-evaluation. External Evaluation. Evaluation Culture.

\section{La cultura de evaluación de la Universidad Federal de Rio Grande do Sul (UFRGS): entre la evaluación externa y la autoevaluación}

\section{Resumen}

Este artículo se propone llevar a cabo una evaluación de la trayectoria de la UFRGS, a partir de entrevistas con los gerentes que estuvieran a frente de la Secretaria de Avaliação Institucional (SAI), desde su creación en los años 2000 hasta 2016 (o sea, cuatro gestores). Se destaca del contexto más general de evaluacion nacional las iniciativas locales que han sido adaptadas para satisfacer las demandas por una evaluacion más global, a través de las administraciones, buscando conocer el foco de trabajo en los diferentes periodos. Busca-se compreender la manera como la UFRGS va construyendo una cultura de evaluación al decorrer del proceso.

Palabras clave: Cultura Interna. Autoevaluación. Evaluación Externa. Cultura de Evaluación. 


\section{Referências}

ALMEIDA, A. N. et al. Effectiveness of public university expansion in Brazil: comparison between the situation of graduated and dropout students. Ensaio: Avaliação e Políticas Públicas em Educação [contectados]. Na imprensa. [citado em 2018-11-10]. Disponível em: https:/www.scielo.br/ scielo.php?script=sci_arttext\&pid=S0104-40362020000200457\&tlng=en. Epub 0104-4036. https://doi.org/10.1590/s0104-40362019002701864

ANDRIOLA, W. B.; ARAÚJO, A. C. Uso de indicadores para diagnóstico situacional de Instituições de Ensino Superior. Ensaio: Avaliação e Políticas Públicas em Educação, Rio de Janeiro, v. 26, n. 100, p. 645-663, jul./set. 2018. https://doi.org/10.1590/s0104-40362018002601062

ANDRIOLA, W. B.; OLIVEIRA, K. R. Autoavaliação institucional na Universidade Federal do Ceará (UFC): meio século de história. Avaliação (Campinas), v. 20, n. 2, p. 489-512, jul. 2015. https://doi.org/10.590/S1414-40772015000200011

BRAGA, A.; LEITE, D. Cultura da avaliação. In: MOROSINI, M. C. (ed.). Enciclopédia de pedagogia universitária: glossário. Brasília, DF: Inep, 2004. Vol. 2, p. 469.

DIAS SOBRINHO, J. A avaliação institucional na Universidade Estadual de Campinas (Unicamp): considerações teóricas e processo. Educación Superior y Sociedad, Caracas, v. 5, n. 1-2, p. 31-49, 1994.

DIAS SOBRINHO, J. Avaliação da Educação Superior. Rio de Janeiro: Vozes, 2000.

FREIRE, P. Pedagogia do oprimido. 50. ed. São Paulo: Paz e Terra, 2011.

GOLDENBERG, M. A arte de pesquisar: como fazer pesquisa qualitativa em ciências sociais. 8. ed. Rio de Janeiro: Record, 2004.

INSTITUTO NACIONAL DE ESTUDOS E PESQUISAS EDUCACIONAIS ANÍSIO TEIXEIRA - INEP. Diretoria de Estudos Educacionais. Censo da Educação Superior, 2010-2013. Brasília, DF, 2015.

LEITE, D. B. C. (coord.). Inovação como fator de revitalização do ensinar e do aprender na Universidade: o caso da avaliação institucional: estudo desenvolvido por grupos interinstitucionais de pesquisa. Porto Alegre: Editora da Universidade, 2000. 
MAGALHÃES, N. M. E. Eu vi um Brasil na TV: televisão e cultura em perspectivas antropológicas. Santa Maria: Editora da Universidade Federal de Santa Maria, 2008.

QUEIROZ, M. I. P. Relatos orais: do 'Indizível' ao 'Dizível'. In: VON SIMSON, O. M. (org.). Experimentos com histórias de vida (Itália-Brasil). Rio de Janeiro: Vértice, 1988. p. 14-43.

RISTOFF, D. I. Os desafios da Educação Superior na Ibero-América: inovação, inclusão e qualidade. Avaliação (Campinas), v. 18, n. 3, p. 519-545, nov. 2013. https://doi.org/10.1590/S1414-40772013000300002

RISTOFF, D. I. Universidade em foco: reflexões sobre a Educação Superior. Florianópolis: Insular, 1999.

RODRIGUES, C. M. C. Proposta de avaliação integrada ao planejamento anual: um modelo para as UCGs. 2003. Tese (Doutorado em Engenharia de Produção) - Universidade Federal do Rio Grande do Sul, Porto Alegre, 2003.

SANTOS, M. G.; LEITE, D. Rede regionais para acreditação e avaliação da qualidade da Educação Superior. Ensaio:

Avaliação e Políticas Públicas em Educação, Rio de Janeiro, v. 27, n. 102, p. 108-128, jan./mar. 2019.

https://doi.org/10.1590/s0104-40362018002701357

VASCONCELOS, I. C. O; GOMES, C. A. Pedagogia dialógica para democratizar a Educação Superior. Ensaio: Avaliação e Políticas Públicas em Educação, Rio de Janeiro, v. 24, n. 92, p. 579-608, jul./set. 2016. https://doi.org/10.1590/S0104-40362016000300004

VERHINE, R. E.; DANTAS, L. M.V.; SOARES, J. F. Do Provão ao ENADE: uma análise comparativa dos exames nacionais utilizados no Ensino Superior Brasileiro. Ensaio: Avaliação e Políticas Públicas em Educação, Rio de Janeiro, v.14, n.52, p. 291-310, jul./set. 2006. https://doi.org/10.1590/S0104-40362006000300002 


\section{Informações das autoras}

Nara Maria Emanuelli Magalhães: Pós-Doutorado em Comunicação Social pela Universidade Federal de Santa Maria. Doutorado em Antropologia Social pela Universidade Federal de Santa Catarina. Pesquisadora do Grupo de Pesquisa Representações, Memória Social e Cidadania do Programa de Pós-Graduação em Comunicação da Universidade Federal do Rio Grande do Sul. Contato: nara.magalhaes@sai.ufrgs.br

iD http://orcid.org/0000-0003-4894-7642

Cláudia Medianeira Cruz Rodrigues: Doutorado em Engenharia de Produção pela Universidade Federal do Rio Grande do Sul. Professora Associada do Departamento de Engenharia de Produção e Transportes da mesma Universidade, Secretária de Avaliação Institucional e Representante Regimental da Comissão Própria de Avaliação. Contato: claudia.rodrigues@producao.ufrgs.br

iD http://orcid.org/0000-0003-1510-6169 